\title{
Decentralised Allocation of Generation in Autonomous Power Networks
}

\author{
J. Frunt, Member, IEEE, and W. L. Kling, Member, IEEE, and J. M. A. Myrzik
}

\begin{abstract}
Due to much larger numbers of small generators it will be more complex to control the balance between supply and demand in future power systems. To deal with this complexity, autonomous power networks could be effective. Autonomous power networks are aggregations of producers and consumers on both physical and economical level and have the capability to control complex systems with simple rules. To demonstrate economic dispatch within an autonomous power network, this paper describes the setup of a model for matching supply and demand within control zones. Next, a method for distributed economic dispatch is incorporated in the model to show how allocation of generators can be executed in a decentralised way.
\end{abstract}

Index Terms-Frequency control, Distributed control, Power generation dispatch, Power system economics, Autonomous power networks.

\section{INTRODUCTION}

$\mathrm{I}_{\mathrm{s} \mathrm{s}}^{\mathrm{n}}$ the European power system, most countries are synchronously interconnected in the Union for the Coordination of Transmission of Electricity (UCTE). This means that the frequency in these countries is always identical (in steady state). The reasons for this interconnection are the increased reliability and the possibility to trade electricity.

Currently about 500 million people are supplied via this grid which together have a maximum load of over $400 \mathrm{GW}$ and a yearly consumption of over $2500 \mathrm{TWh}$ [1]. Most of the electricity in the grid is generated with synchronous generators. The frequency of the grid is created by these rotating machines. As long as supply and demand of electricity are in balance, the frequency of the grid will remain nominal. However, any imbalance between supply and demand will be compensated by a change in the stored kinetic energy of the rotating machines thus leading to a frequency deviation. Frequency deviations should remain within certain limits to avoid blackouts or damaged equipment. To ensure this, several control strategies have been incorporated into the power system.

Due to the integration of distributed generators, which are less predictable and poorly controllable, in future power systems it will be more complex to control the balance between supply and demand [2], [3]. One of the solutions is to set up so-called autonomously operated power networks interconnected within the future grid [4]. Autonomous power networks are aggregations of producers and consumers of

This work was supported by the Dutch Ministry of Economic Affairs as an EOS-project. electricity on both physical and economical level. To the outside world an autonomous power network behaves as a single entity which is capable of trading energy. More details on the concept of autonomous networks is given in [5] where it is stated that autonomous networks are power networks which remain part of the total grid but for the rest in principle are fully self controlled. Each autonomous power network ensures its own balance between supply, demand and import or export internally. Based on the marginal costs for different services, generators and loads within the autonomous power network are controlled either autonomously, while ensuring the requirements for trade and taking constraints into account. To evaluate the effect of distributed generators and autonomous power networks on the power balance in the system, a simulation model was created.

This paper describes the setup of this model by explaining all its components in detail. First an overview of the complete model is given in section II. Section III describes the individual components. The model is verified with measurement data. Some results are shown in section IV. Autonomous power networks should be controlled internally such that they provide power and ancillary services at the lowest costs. Section V gives two methods to control units in autonomous power networks both in a centralised and a decentralised way. It is shown that cost minimisation by allocation of generators is possible without centralised aggregation. Conclusions of the study are given in section VI.

\section{MODEL DESCRIPTION}

The model considers the dynamic behaviour of a single control zone within a larger synchronous grid. Within one control zone, different production facilities are present. The other control zones are modelled as one single block with inertia. The full model is displayed in figure 1 .

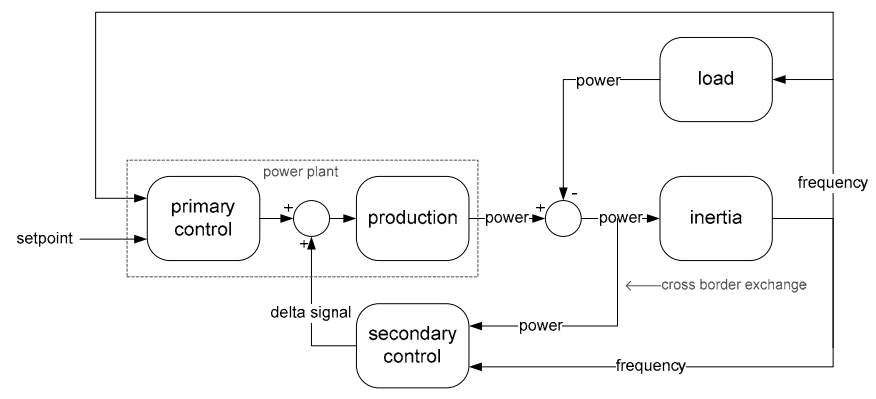

Fig. 1. Block scheme of the frequency stability model 
Electricity is produced by the production block. The load in the control zone is subtracted from this production. For simplicity it is assumed that the scheduled cross-border exchange is equal to zero. Thus, the difference between load and supply is the imbalance of the modelled control zone. Imbalance within the modelled control zone causes a frequency deviation in the whole network, for which the total inertia is important. This frequency deviation activates primary control. The combination of cross-border exchange and the frequency deviation activates secondary control. Both controllers aim to stop the frequency deviation and to bring back the frequency to its nominal value. In the next subsections the individual blocks are explained in detail.

\section{BLOCK DESCRIPTION}

The model, as explained in section II consists of several parts.

\section{A. Production}

The production block for the control considered here consists of either coal or gas fired production plants. The basic model for production is derived from Roffel and de Boer [6] who suggest using a fast and a slow part to model power plants. According to [6] the transfer function of a power plant can be approximated by (1), (2) and (3).

$$
\begin{aligned}
& H_{\text {fast }}(s)=\frac{\tau_{H} s}{\tau_{H} s+1} \cdot \frac{K}{\tau_{L} s+1} \\
& H_{\text {slow }}(s)=\frac{e^{-\theta s}}{\tau s+1} \\
& H(s)=H_{\text {fast }}(s)+H_{\text {slow }}(s)
\end{aligned}
$$

The constants in these equations should have the following values (Table I) according to [6].

\begin{tabular}{|c|c|c|c|c|c|}
\hline & $\tau_{\mathrm{H}}$ & $\tau_{\mathrm{L}}$ & $\mathrm{K}$ & $\theta$ & $\tau$ \\
\hline Gas & $25 \mathrm{~s}$ & $12.5 \mathrm{~s}$ & 1.5 & $10 \mathrm{~s}$ & $17 \mathrm{~s}$ \\
\hline Coal & $85 \mathrm{~s}$ & $10.0 \mathrm{~s}$ & 1.2 & $30 \mathrm{~s}$ & $60 \mathrm{~s}$ \\
\hline
\end{tabular}

TABLE I

TIME CONSTANTS

Using the data from table I, step responses for coal and gas fired plants can be derived (Fig. 2). The step response consists of a fast and slow reacting part. The fast section is the result of opening the steam valves while the slow section is due to the increased fuel input. For the step response it is assumed that the power plant is already being operated close to its nominal operation point and the change in set point for the step response is small compared to the total capacity of the unit.

\section{B. Load}

The load in the model is designed as a constant which will be influenced by the frequency. Because the load partly consists of rotating machines, that release kinetic energy as their rotating speed decreases, the load has a self-regulating effect. According to UCTE [7] this self-regulating effect is between $1 \%$ and $2 \%$ per Hertz.

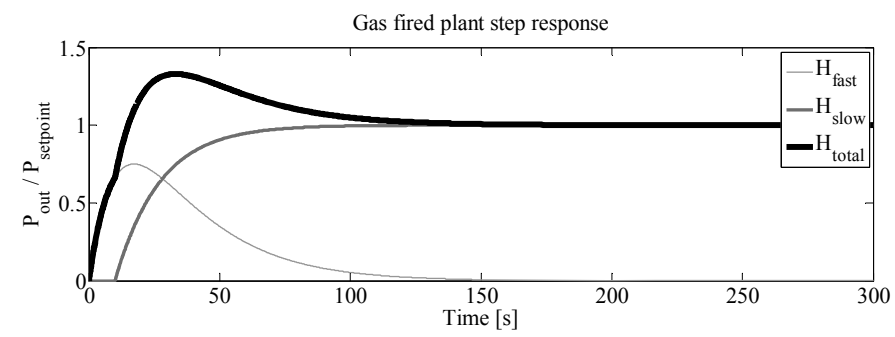

Coal fired plant step response

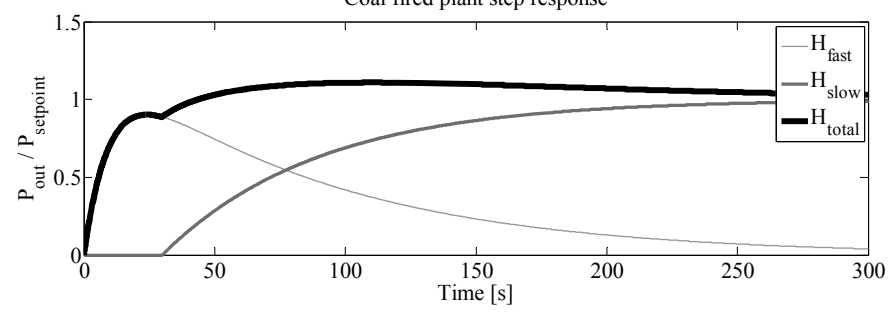

Fig. 2. Step responses of gas (upper figure) and coal (lower figure) fired power plants

\section{Grid inertia}

Imbalance causes a frequency deviation [8]. The speed at which a certain imbalance creates this frequency deviation depends on the total inertia of the interconnected grid [7]. Furthermore, the frequency deviation is influenced by the selfregulating effect of all other loads (outside of the control zone under study), as indicated before. The inertia block is therefore modelled as follows (Fig. 3).

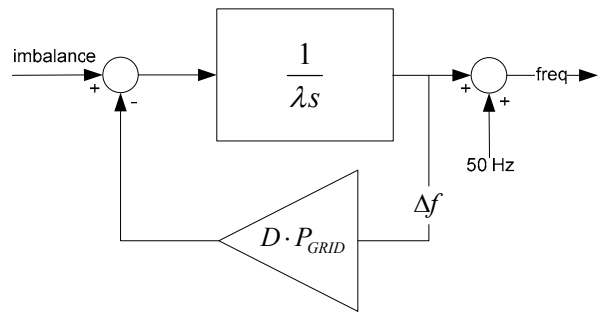

Fig. 3. Inertia block for an interconnected grid

The imbalance damping effect depends on the current load in the network $\left(\mathrm{P}_{\mathrm{GRID}}\right)$ and the self-regulating effect $(\mathrm{D})$. In the model the variables $\mathrm{P}_{\mathrm{GRID}}$ and $\mathrm{D}$ have values of $300 \mathrm{GW}$ and $2 \%$ respectively.

The inertia of the UCTE grid was determined based on frequency measurements from TenneT TSO B.V. for which it was known what the imbalance in the network was. The inertia of the grid is defined by (4).

$$
\lambda=\frac{\Delta P}{\Delta f}
$$

Here $\Delta \mathrm{P}$ is the imbalance and $\Delta \mathrm{f}$ is the frequency deviation which is measured some seconds after the occurrence of the imbalance. $\lambda$ is called the network power frequency characteristic. According to a statistical analysis the value of $\lambda$ is between $19000 \mathrm{MW} / \mathrm{Hz}$ and $47000 \mathrm{MW} / \mathrm{Hz}$ with a mean value of $26000 \mathrm{MW} / \mathrm{Hz}$. According to UCTE [7] this value 
should have a minimum of $18000 \mathrm{MW} / \mathrm{Hz}$. In figure 4, several situations have been analysed leading to values of 27000 $\mathrm{MW} / \mathrm{Hz}, 38000 \mathrm{MW} / \mathrm{Hz}$ and $29000 \mathrm{MW} / \mathrm{Hz}$. A replacement of large synchronous generators by distributed generation, which is often based on inverters with power electronics, could result in a decrease of inertia [9]. As a consequence, sudden imbalances will result in larger frequency deviations.

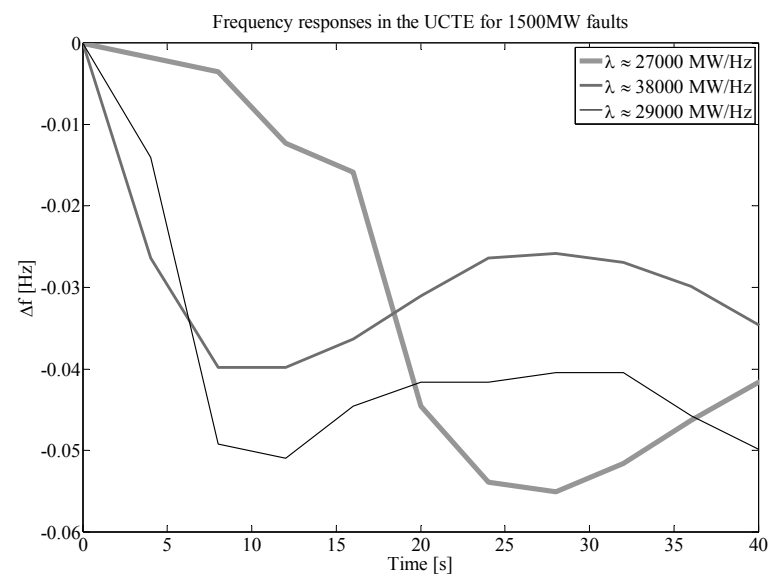

Fig. 4. Three $1500 \mathrm{MW}$ power loss events in the UCTE grid with different values for $\lambda$.

\section{Primary control}

Primary control has the aim to continuously maintain the balance between supply and demand. The primary controller increases the set point of a power plant proportionally with the frequency deviation. Primary controllers work with a droop function which is defined with (5).

$$
s=\frac{\Delta f / f_{\text {nom }}}{\Delta P / P_{\text {nom }}}
$$

Here $\Delta f, f_{n o m}, \Delta P$ and $P_{\text {nom }}$ are the frequency deviation, the nominal frequency, the change in set point and the nominal set point respectively.

The droop defines the relative change in frequency deviation that results in a specific relative change in power production. A smaller value for the droop means that a primary controller reacts more to frequency deviations. According to UCTE [7], the droop for each power plant should be set to $10 \%$. However, in practice parties do sometimes choose to set the droop on a lower value thus increasing their share in frequency control. The goal of primary control is to stop the frequency deviation and to hold the frequency at a so-called quasi-steady-state value.

\section{E. Secondary control}

After primary control has stabilised the frequency deviation, secondary control is activated to restore the frequency from the quasi-steady-state value to its nominal value. The secondary controller is slower than the primary controller and it is only active in the control zone where the imbalance is caused. Therefore secondary control is not only based on frequency measurement but it also takes the unscheduled (being the difference between the actual and the scheduled) cross-border flows into account. A secondary controller uses an integral controller to regulate the area control error (ACE) to zero. The ACE is defined in (6).

$$
A C E=P_{\text {meas }}-P_{\text {sched }}+K \cdot \Delta f
$$

Here $\mathrm{P}_{\text {meas }}$ is the actual cross-border flow, $\mathrm{P}_{\text {sched }}$ is the scheduled cross-border flow. $\mathrm{K}$ is a constant (in $\mathrm{MW} / \mathrm{Hz}$ ) which is defined for each control zone based on its characteristics and $\Delta \mathrm{f}$ is the frequency deviation. Currently the transmission system operators calculate the ACE. This ACE is then processed (smoothened) to a processed area control error. A proportional integral controller converts the processed area control error into a total delta signal, which is then split into several delta signals, using selection criteria which may be based on market mechanisms. The delta signals represent the change in set point that each utility should apply to contribute to secondary control. Based on discussions with experts of the transmission system operator in the Netherlands it was decided to include a delay between the calculation of the delta signal and changing the set point to have a more realistic response from the model. This time corresponds to the time which parties take to respond to a delta signal.

\section{VERIFICATION OF THE MODEL}

The results of the model can be verified using frequency measurements. For each series of measurements, in which a frequency deviation occurs, it was known what caused this frequency deviation. The model can be used to simulate this event and the system variables can be adjusted such that the output of the model fits with the measurements. For a number of events the results of the model are given. In figures $5 \mathrm{a}, 5 \mathrm{~b}$ and $5 \mathrm{c}$ for three different events the measurements are shown and the simulations with the model are given.

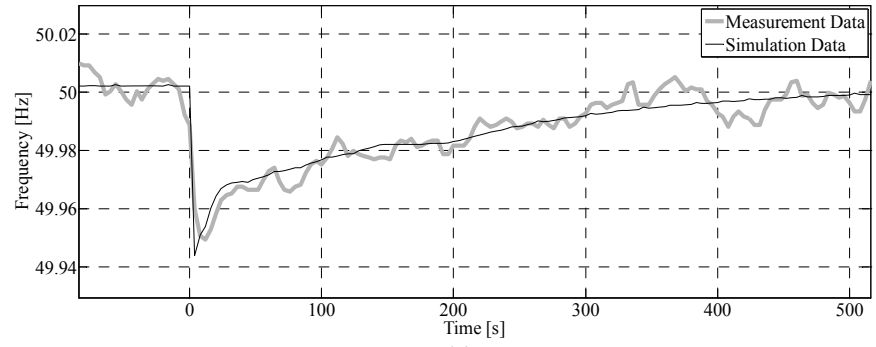

(a)

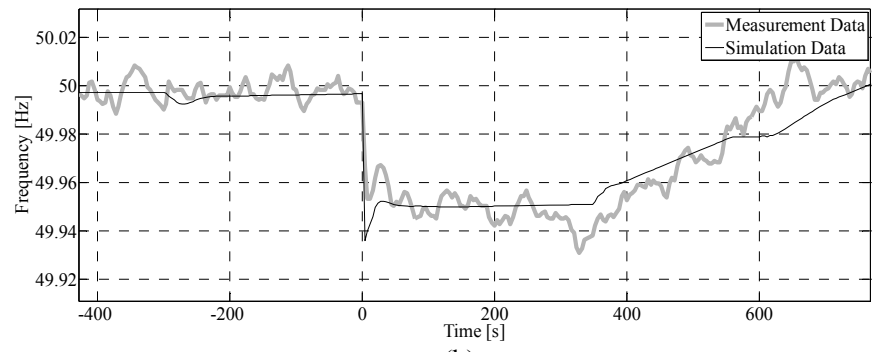

(b) 


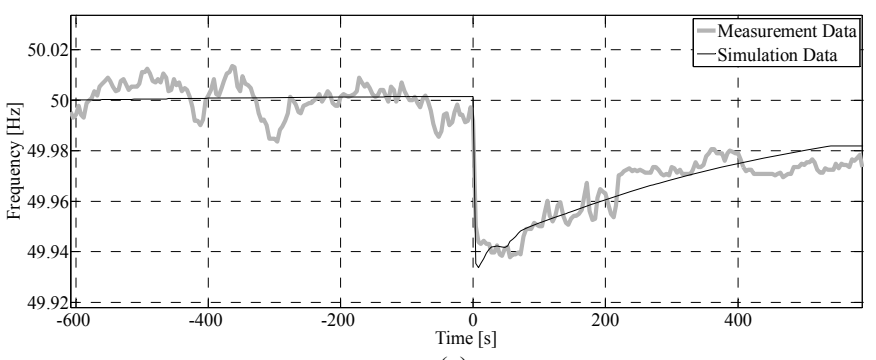

(c)

Fig. 5. Frequency responses for three different events ( $a, b$ and $c)$. The grey line shows measurement data while the black line shows the response of the model. The faults simulated are two $1500 \mathrm{MW}$ and one $1300 \mathrm{MW}$ failures respectively that took place in the UCTE network in 2005.

It can be concluded that events can be simulated with this model accurately. In figure $5 \mathrm{~b}$ it is clear that the secondary control action is delayed by market players as mentioned before in section III.E. The delay was only included in example $b$ since from measurements it was concluded that market players in this case took more time (approx. $350 \mathrm{sec}$.) to respond to the delta signal.

\section{ECONOMIC DISPATCH}

As described in the introduction of this paper, future power systems will incorporate larger shares of less predictable and poorly controllable distributed generation. Autonomous power networks might enable the introduction of distributed generation. In this section, the concept of autonomous power networks will be explained, after which a method for economic dispatch within a single autonomous power network is discussed using the dynamic model explained before.

\section{A. Autonomous power networks}

According to Jokic [4] autonomous power networks are aggregations of producers and consumers on both physical and economical level in a relatively small area compared to the total grid. Towards the outside world autonomous power networks behave as single entities with a certain net production or consumption. Each autonomous power network might be operated by a market agent which is capable of trading both energy on power markets and ancillary services (for balance management, congestion management, etc.) on specific markets. To be able to do this, each market agent must be aware of the available capacities for both power generation and ancillary services within the autonomous power network.

Jokic [4] describes a mechanism based on nodal prices to control a system with multiple autonomous power networks. Power flow between autonomous power networks is based on their nodal prices. These nodal prices depend on the costs to produce electrical energy inside the autonomous power network and congestion of connections between the autonomous power networks. Inside the autonomous power network, different generators and loads are operational. Depending on the scheduled import, export and load in the autonomous power network, an allocation of generators will be made. This allocation is usually based on marginal costs.

Autonomous power networks entail a market agent which decides upon trade of energy and ancillary services with other autonomous power networks. It is capable of doing this since it has information on the costs of the different services (energy and ancillary services). The internal functioning of an autonomous power network is modelled using the model explained before. It is assumed that an autonomous power network has multiple producers and the 'power plant' block in figure 1 is replaced by multiple power plants in parallel. Furthermore, for simplicity, it is assumed that the autonomous power network is not trading any energy with other autonomous power networks, thus on beforehand supply and demand within the network must be in balance and its area control error must be controlled to zero. In order to keep this balance, the autonomous power network has control power available for primary and secondary control.

\section{B. Dispatch by aggregation}

Inside a single autonomous power network an optimal selection of resources must be made to supply the required amount of power and the ancillary services in an optimal way. This optimisation can either be done by the market agent via dispatch or locally in all units of the autonomous power network. If the selection of internal resources is to be made by the autonomous market agent, the agent must have access to individual information of its producers and consumers.

The conventional way to optimise the allocation of producers is by aggregating their individual supply curves per unit of time into an aggregated curve. The individual shares to production for the next period of time can then be derived from each individual curve and the aggregated curve. This is explained in figure 6.

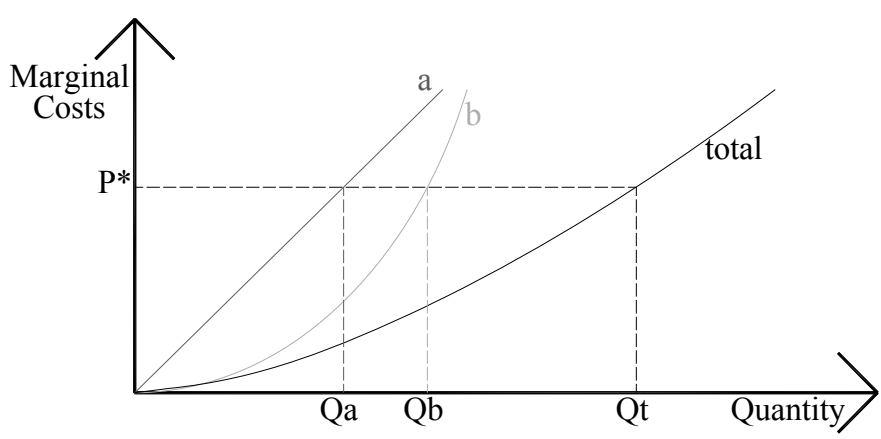

Fig. 6. Economic dispatch by aggregation. Curves ' $\mathrm{a}$ ' and ' $\mathrm{b}$ ' are aggregated to 'total'. The individual productions of ' $\mathrm{A}$ ' and ' $\mathrm{B}$ ' are ' $\mathrm{Qa}$ ' and ' $\mathrm{Qb}$ '.

Suppose two supply curves ' $a$ ' and ' $b$ ' for two producers ' $A$ ' and ' $B$ ' respectively. The aggregated curve is given by the 'total'. For simplicity the demand is supposed to be inelastic and equal to ' $\mathrm{Qt}$ '. The corresponding marginal costs are ' $\mathrm{P}$ ', At the intersection points of ' $\mathrm{P}$ *' and the curves ' $\mathrm{a}$ ' and ' $\mathrm{b}$ ', the quantities ' $\mathrm{Q} a$ ' and ' $\mathrm{Qb}$ ' for producers ' $\mathrm{A}$ ' and ' $\mathrm{B}$ ' can be found. The main advantage of this dispatch technique is that it can handle all different types of supply curves. The main disadvantage of this technique is that the dispatch centre (or market agent) needs to have all supply curves to be able to define the aggregated supply curve.

One conclusion from figure 6 is that the individual marginal costs (MC) for ' $a$ ' and ' $b$ ' are identical in the optimum. This is proven by Denny [10] and Brabandere [11] and can be 
explained by the fact that if the producers would not have equal marginal costs, it would have been more efficient to have the cheaper producer produce more and the expensive producer produce less. Equation (7) gives this minimisation problem with the constraints (8) and (9).

$$
\min _{Q \in \mathbb{R}^{n}} \sum_{i=1}^{n} \int_{0}^{Q_{i}} M C_{i}(q) d q
$$

Subject to:

$$
\begin{aligned}
& Q \geq 0 \\
& \sum_{i=1}^{n} Q_{i}=\text { Demand }
\end{aligned}
$$

According to what is stated above it results in (10) and (11).

If:

$$
Q^{*}=\arg \min _{Q \in \mathbb{R}^{n}} \sum_{i=1}^{n} \int_{0}^{Q_{i}} M C_{i}(q) d q
$$

Then:

$$
M C_{1}\left(Q_{1}^{*}\right)=M C_{2}\left(Q_{2}^{*}\right)=\ldots=M C_{n}\left(Q_{n}^{*}\right)
$$

In (7) to (11) $\mathrm{MC}_{\mathrm{i}}(\mathrm{q})$ are the incremental cost functions for the $\mathrm{n}$ different producers as a function of quantity $\mathrm{q}, \mathrm{Q}_{\mathrm{i}}^{*}$ are the optimal set points for the $\mathrm{n}$ producers and Demand is the total amount to be produced. The optimisation has to minimise total costs in the system and the constraints state that the production of all suppliers should be nonnegative and that the total production should always be equal to the demand. For most cases this optimisation problem can be solved analytically showing that the optimum is in that point where the marginal costs are equal for all producers.

\section{Distributed dispatch}

The assumption that total costs are minimal at that point where all incremental costs are equal can be used to control different units within an autonomous power network. By calculating the average marginal costs for all units within the network and comparing this with their individual marginal costs it can be determined whether a producer should either increase or decrease its production. When all producers produce at the same marginal costs their individual marginal costs will be equal to the average marginal costs and optimal dispatch has been achieved. Locally, only information on the own marginal costs and the estimated average marginal costs are required. Therefore different producers in the model of this research are supposed to be equipped with a marginal cost function which gives the marginal costs as a continuous and monotonically increasing function of their output up to its maximum capacity. This value is sent to a controller which continuously compares it with the estimated average marginal costs in the network and determines whether to increase or decrease production. This action is modelled as an integral function. The controller receives the value for estimated average marginal costs from any other controller in the network. The controller also derives the new estimated average marginal costs by taking the mean of the previous estimated average and its current local marginal costs and sends it to the next controller for another producer. The order of communication between controllers can either be based on geographical location or any random selection. The initial set point of the estimated average marginal costs, which the first controller uses, can have any value between the possible minimum and maximum marginal costs. This value will quickly converge to the actual estimated average costs value. The structure is shown in figure 7. The multiple plants and controllers in this figure provide inputs for the power plant block in figure 1 .

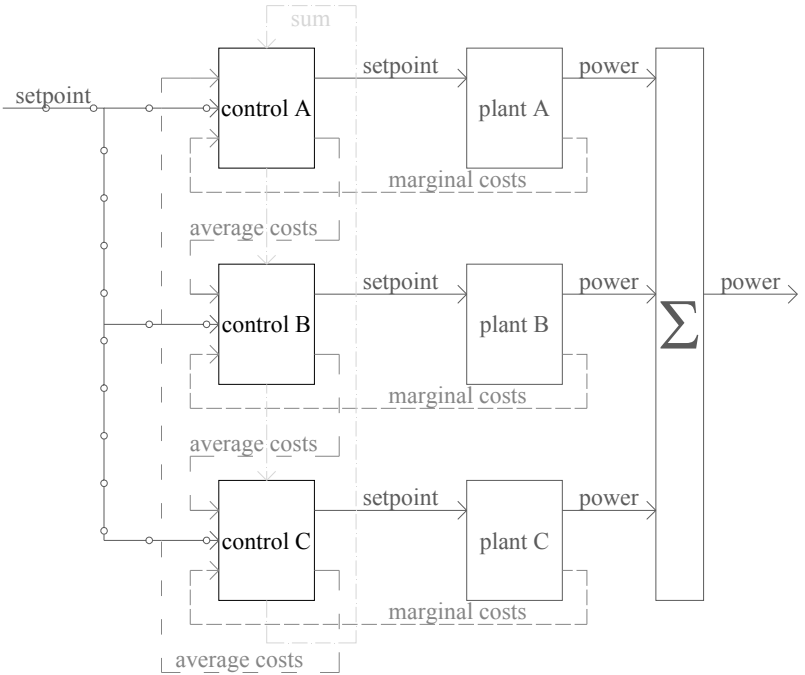

Fig. 7. Control structure for distributed dispatch using marginal costs, the average marginal costs and the sum of the set points.

Each producer has its own controller which receives the total set point (i.e. total demand). The controllers continuously determine the individual set point for all individual plants. To ensure that the economic dispatch controller does not influence the balance between supply and demand, also the sum of set points need to be controlled in a decentralised way.

In the control structure displayed in figure 7, the values for the estimated average marginal costs and the total set point are sent to the next controller thus creating a loop. However a control structure in which this data is sent to a randomly selected other controller also proves to function. This change would actually increase reliability since a fault in communication between two controllers would not interrupt the system's operation. After all, communication with other controllers would continue to exist. However, this also increases the complexity of the system since more communication links need to be created. More about this has been written by Brabandere [11] and Vanthournout [12].

The complete economic dispatch control loop is outside the primary and secondary control loops and is therefore not 
influencing balance management. However an identical control structure can be used to split up the total delta signal for secondary control into different set point for different producers.

\section{Results of the dispatch controller}

A simulation was performed including the economic dispatch controllers. During this simulation part of the production capacity is lost at $\mathrm{t}=0 \mathrm{sec}$. Since the marginal costs are a function of the power output of the running units, a loss of production will lead to an increase of the costs. The figures $8 \mathrm{a}, 8 \mathrm{~b}, 8 \mathrm{c}$ and $8 \mathrm{~d}$ show the production of three producers $\mathrm{A}, \mathrm{B}$ and $\mathrm{C}$, the frequency of the grid, the real-time marginal costs for all three producers and the delta-signal to $\mathrm{A}, \mathrm{B}$ and $\mathrm{C}$.

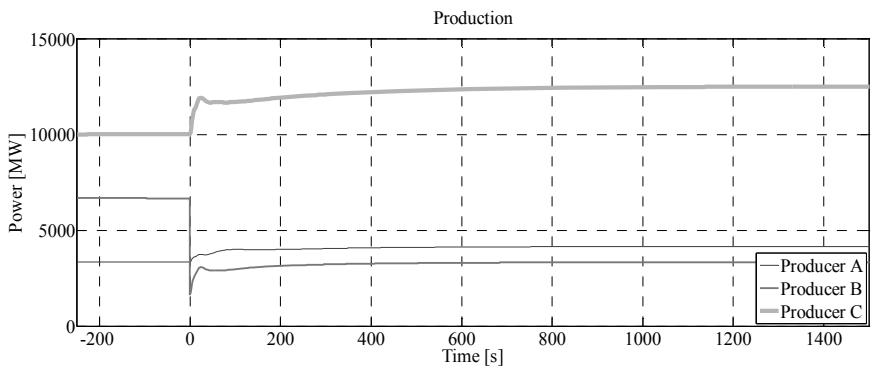

(a)

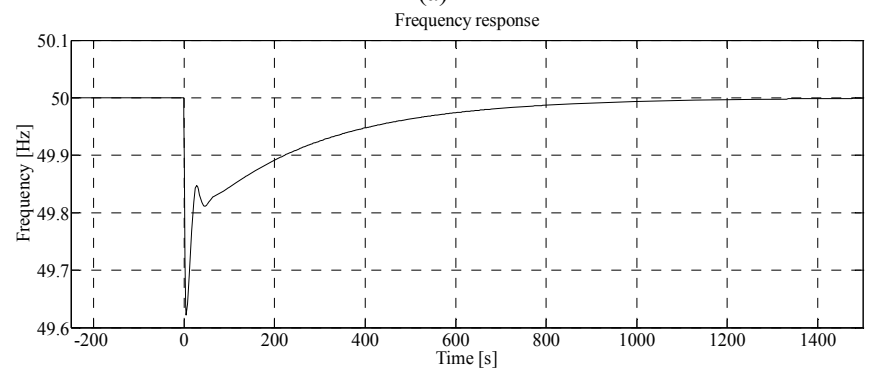

(b)

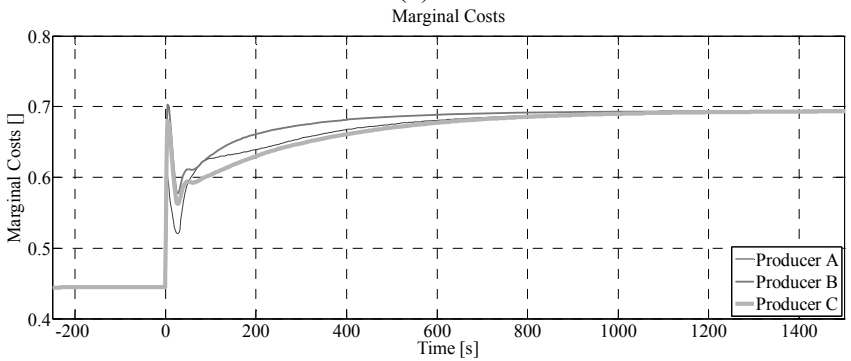

(c)

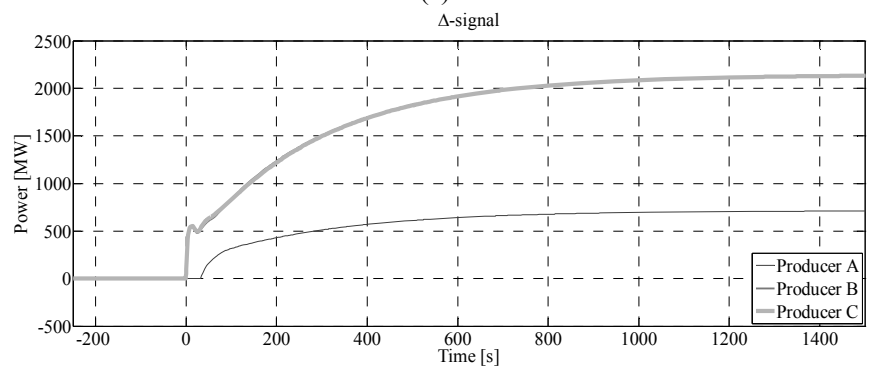

(d)

Fig. 8. Results of the model with the decentralised economical dispatch

Before the loss of production all three producers produce at the same marginal costs. At $\mathrm{t}=0 \mathrm{sec}$. there is loss of production for producer $\mathrm{B}$ and all marginal costs will deviate before converging again in a new economic optimum. Due to the loss of production all costs are higher at the second optimum. It can be seen that the frequency is restored in a normal way also.

In this model transport capacity limitations and transmission losses are not taken into account. However, these can be included by altering the marginal cost functions, thus influencing the end results.

\section{CONCLUSIONS}

In this paper insight information was given on a model to simulate the frequency response of a synchronously interconnected electricity grid. The different (i.e. primary and secondary) control mechanisms can be evaluated using this model. The model was used to discuss economic dispatch in autonomous power networks. Although dispatch is usually performed on a central level per unit of time by utilities or market agents that need full insight in the supply curves for each unit to perform this action, it is also possible to perform a distributed dispatch of units inside autonomous power networks which are considered to be the building blocks of future power systems with higher penetration of distributed generation. It is shown that, by comparing the individual marginal costs with the estimated average marginal costs in the network, a control structure with distributed dispatch does not require full insight on all supply curves of all plants to continuously achieve economically optimal dispatch. Only the momentaneous marginal costs of a single plant and an estimation of the average marginal costs are of interest for the optimisation. Further research will include the integration of block biddings and start-up costs of power plants.

\section{ACKNOWLEDGMENT}

This article is part of the project Regelduurzaam, which is an EOS-project (Energy Research Subsidy Project) funded by the Dutch Ministry of Economic Affairs. The authors acknowledge TenneT TSO B.V. for the provision of frequency measurement data.

\section{REFERENCES}

[1] Union for the co-ordination of transmission of electricity, "Memo 2007," UCTE, Belgium, [Online]. Available: http://www.ucte.org/ library/memos/memo 2007.pdf.

[2] J. J. Meeuwsen, and J. M. A. Myrzik, and G. P. J. Verbong, and W. L. Kling, and J. H. Blom, "Electricity networks of the future: various roads to a sustainable energy system," in Cigré session 2008, Paris, France, 2008.

[3] Ministry of Economic Affairs, "Energierapport 2008," The Netherlands, [Online]. Available: http://appz.ez.nl/publicaties/pdfs/08ET14.pdf.

[4] A. Jokic, "Price-based optimal control of electrical power systems," Ph.D. dissertation, Dept. Elec. Eng., Eindhoven Univ. of Technology, 2007.

[5] F. Provoost, and A. Ishchenko, and A. Jokic, and J. M. A. Myrzik, and W. L. Kling, "Self controlling autonomous operating power networks," in CIRED $18^{\text {th }}$ International Conference on Electricity Distribution, Turin, Italy, 2005.

[6] B. Roffel, and W. W. de Boer, "Analysis of power and frequency contro requirements in view of increased decentralised production and market liberalization," Control Engineering Practice, vol. 11, no. 4, pp. 367375, Apr. 2003. 
[7] Union for the co-ordination of transmission of electricity, "Operational handbook," UCTE, Belgium, [Online]. Available: http://www.ucte.org/publications/ophandbook/.

[8] P. Kundur, Power system stability and control, McGraw-Hill Inc., 1994, pp. 581-626.

[9] B.C. Ummels, M. Gibescu, W.L. Kling, and G.C. Paap, "Development of a simulation model for secondary control performance assessment with significant wind power in a market environment," in $16^{\text {th }}$ Power Systems Computations Conference, Glasgow, Scotland, 2008.

[10] F.I. Denny, and D.E. Dismukes, Power System Operations and Electricity Markets, vol. I. Boca Raton: CRC Press, 2002, chapter 9.

[11] K. De Brabandere, "Voltage and frequency droop control in low voltage grids by distributed generators with inverter front-end," Ph.D. dissertation, Dept. Elec. Eng., Leuven Univ. of Technology, 2006.

[12] K. Vanthournout, "A semantic overlay network based robust datainfrastructure, applied to the electric power grid," Ph.D. dissertation, Dept. Elec. Eng., Leuven Univ. of Technology, 2006.

\section{BIOGRAPHIES}

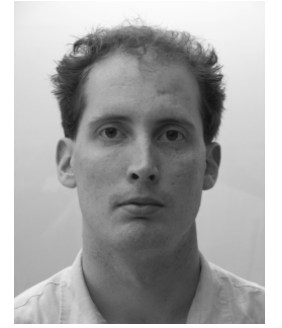

Jasper Frunt was born in 's-Hertogenbosch in 1981 $\mathrm{He}$ received his $\mathrm{B}$. degree in electrical engineering in 2003 from the University of Professional Education in 's-Hertogenbosch. In 2006 he received his M.Sc. degree in sustainable energy technology from Eindhoven University of Technology. For his graduation projects he worked with Kema N.V. and Tennet TSO bv (Dutch Transmission System Operator) respectively. Currently he is a $\mathrm{PhD}$ in the EOS (Energy Research Subsidy) project 'Regelduurzaam' for Eindhoven University of Technology. His research focuses on current and future deployment, legislation and organisation of control power for balance management.

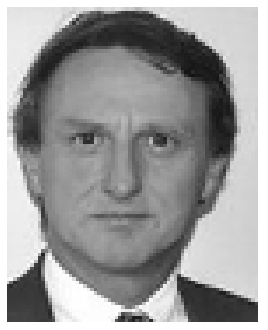

Wil L. Kling received his M.Sc. degree in electrical engineering from the Technical University of Eindhoven in 1978. Since 1993 he has been a (parttime) professor in the Department of Electrical Engineering at Delft University of Technology, in the field of Power Systems Engineering. In addition, he is with the Transmission Operations department of TenneT (the Dutch Transmission System Operator). Since 2000, he has also been a part-time professor at the Technical University of Eindhoven. His area of interest is related to planning and operations of power systems. Prof. Kling is involved in scientific organisations such as CIGRE and the IEEE. As Netherlands' representative, he is a member of CIGRE Study Committee C6 Distribution Systems and Dispersed Generation, and the Administrative Council of CIGRE.

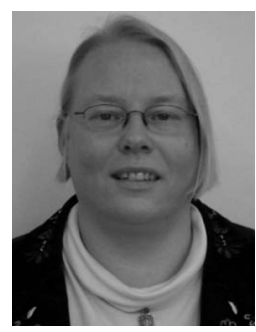

Johanna M. A. Myrzik was born in Darmstadt, Germany in 1966. She received her MSc. in Electrical Engineering from the Darmstadt University of Technology, Germany in 1992. From 1993 to 1995 she worked as a researcher at the Institute for Solar Energy Supply Technology (ISET e.V.) in Kassel, Germany. In 1995 Mrs. Myrzik joined to the Kassel University, where she finished her $\mathrm{PhD}$ thesis in the field of solar inverter topologies in 2000. Since 2000, she is with the Eindhoven University of Technology, the Netherlands. In 2002, Mrs. Myrzik became an assistant professor in the field of distributed generation. Her fields of interests are: power electronics, renewable energy, distributed generation, electrical power supply. 